\title{
Ultrasound-guided hydrostatic reduction versus fluoroscopy-guided air reduction for pediatric intussusception: a multi-center, prospective, cohort study
}

\author{
Shu Ting Liu ${ }^{1 \dagger}$, Xiao Bing Tang ${ }^{1 \dagger}$, Huan Li ${ }^{2}$, Dong Chen ${ }^{3}$, Jun Lei ${ }^{4}$ and Yu Zuo Bai ${ }^{1,5^{*}}$
}

\begin{abstract}
Background: Intussusception is the most common abdominal emergency in children. The first line treatment of uncomplicated pediatric intussusception is enema reduction. Until now, there have been no multi-center studies comparing the effectiveness and safety of UGHR and FGAR in the treatment of pediatric intussusception. The aim of this study was to compare the effectiveness and safety of the two most commonly used enema methods of pediatric intussusception: ultrasound-guided hydrostatic reduction (UGHR) and fluoroscopy-guided air reduction (FGAR).
\end{abstract}

Methods: From November 1, 2017 to October 31, 2018, we conducted a multi-center, prospective, cohort study. Children diagnosed with intussusception in four large Children's Medical Centers in China were divided into UGHR and FGAR groups. Stratified analysis and subgroup analysis were used for further comparison. The success and recurrence rates were used to evaluate the effectiveness of enema reduction. The perforation rate was used to evaluate the safety of enema reduction.

Results: A total of 2124 cases met the inclusion criteria (UGHR group: 1119 cases; FGAR group: 1005 cases). The success and recurrence rates in the UGHR group were higher than in the FGAR group (95.80\%, 9.28\% vs. 93.13\%, 10.65\%) $(P<0.05, P>0.05)$, respectively. The perforation rate in the UGHR group was $0.36 \%$ compared with $0.30 \%$ in the FGAR group $(P>0.05)$. Subgroup analysis showed the success rates in the UGHR group were higher than in the FGAR group of patients with onset time between 12 and $24 \mathrm{~h}(95.56 \%$ vs. 90.57\%) $(P<0.05)$. Of patients aged 4 to 24 months, the success rates in the UGHR group were also higher than in the FGAR group (95.77\% vs. 91.60\%) $(P$ $<0.05$ ). Stratified analysis showed the success rates in the UGHR group were higher than in the FGAR group in patients with the symptom of bloody stool (91.91\% vs $85.38 \%)(P<0.05)$.

(Continued on next page)

\footnotetext{
* Correspondence: baiyz1216@126.com

†Shu Ting Liu and Xiao Bing Tang contributed equally to this work.

'Department of Pediatric Surgery, Shengjing Hospital, China Medical

University, No. 36 Sanhao Street, Heping District, Shenyang 110004, P. R.

China

${ }^{5}$ The Pediatric Anorectal Group, Society of Pediatric Surgery, Chinese Medical

Association, Shenyang, China

Full list of author information is available at the end of the article
}

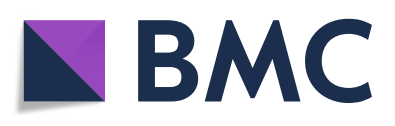

(- The Author(s). 2021 Open Access This article is licensed under a Creative Commons Attribution 4.0 International License, which permits use, sharing, adaptation, distribution and reproduction in any medium or format, as long as you give appropriate credit to the original author(s) and the source, provide a link to the Creative Commons licence, and indicate if changes were made. The images or other third party material in this article are included in the article's Creative Commons licence, unless indicated otherwise in a credit line to the material. If material is not included in the article's Creative Commons licence and your intended use is not permitted by statutory regulation or exceeds the permitted use, you will need to obtain permission directly from the copyright holder. To view a copy of this licence, visit http://creativecommons.org/licenses/by/4.0/. The Creative Commons Public Domain Dedication waiver (http://creativecommons.org/publicdomain/zero/1.0/) applies to the data made available in this article, unless otherwise stated in a credit line to the data. 
(Continued from previous page)

Conclusions: UGHR and FGAR are safe, nonsurgical treatment methods for acute pediatric intussusception. UGHR is superior to FGAR, no radiation risk, its success rate is higher, without a difference in perforation rate, especially for patients aged 4-24 months.

Level of evidence: Level II.

Keywords: Intussusception, Enema reduction, Multicenter study, Pediatric, Hydrostatic, Fluoroscopy

\section{Introduction}

Intussusception is one of the most common abdominal emergencies in infants and toddlers, typically occurring in infants between 4 and 10 months. After 2 years of age, the incidence of intussusception declines $[1,2]$. Delayed diagnosis and treatment may lead to intestinal necrosis or even death. The definition of intussusception is given as the invagination of one segment of intestine into a segment of distal intestine. Common symptoms and signs include colicky abdominal pain, vomiting, palpable abdominal mass, and currant jelly stool.

The treatment methods of pediatric intussusception are divided into two types: surgical treatment or nonsurgical treatment. For uncomplicated pediatric intussusception, imaging-guided enema reduction is the internationally recognized, standard, nonsurgical treatment method [3], which can cure the vast majority of intussusception cases. Operation is mainly performed in patients for whom nonsurgical treatment has failed or those with complicated intussusception.

Both hydrostatic and air enemas can be used to reduce intussuscepted bowel, under the guidance of either fluoroscopy or ultrasonography. The preferred method of enema reduction is not standardized. There is practice variability among different institutions regarding to the type of enema (air or liquid) used and different international guidelines. Currently, ultrasound-guided hydrostatic reduction (UGHR) and fluoroscopy-guided air reduction (FGAR) are the most commonly used nonsurgical treatment methods $[4,5]$, the indications and contraindications of which are basically the same. There are only a few studies comparing the effectiveness and safety of UGHR and FGAR in the literature [6-9], and no clear consensus has been reached regarding the optimal reduction strategy. Some studies demonstrated a higher success rate of UGHR $[7,8]$, while some studies demonstrated a higher success rate of FGAR $[6,9]$. Till now, there was no multi-center prospective study for UGHR and FGAR in the treatment of pediatric intussusception in the world.

In order to find the optimal treatment method for pediatric intussusception, we conducted a multi-center, prospective clinical study with a large number of intussusception cases to compare the effectiveness and safety of UGHR and FGAR in the treatment of pediatric intussusception.

\section{Methods}

\section{Study design}

This was a multi-center, prospective, observational cohort study with the purpose of comparing the effectiveness and safety of UGHR and FGAR in pediatric intussusception patients. It included four large children's medical centers from different regions of China: Shengjing Hospital of China Medical University, Xi'an Children's Hospital, Wuhan Children's Hospital, and Jiangxi Provincial Children's Hospital. This study was approved by the Institutional Review Board of Shengjing Hospital of China Medical University (Approval No.2019PS601K), and has been exempted from the application for informed consent.

\section{Participants and data collection}

Patients under 14 years old who were diagnosed with intussusception (ICD-10 code K56.1) and underwent enema reduction between November 1, 2017 and October 31, 2018 were entered into this study.

The data inclusion criteria were as follows: (1) intussusception is diagnosed by ultrasound with characteristic image; (2) the onset time is less than $48 \mathrm{~h}$; (3) aged between 4 months and 14 years; (4) a well general condition and no signs of peritonitis; (5) no clinical manifestations of small intestinal obstruction; and (6) patients who suffer from intussusception again within 1 month are considered as recurrence of intussusception.

Patients' clinical data was recorded, including patient's gender, age, admission time, onset time, main symptoms, concentric circle size on ultrasound, and outcome of enema reduction.

\section{Grouping}

According to the conventional enema reduction method used in the four hospitals, the cases were divided into two groups: a UGHR group and a FGAR group. Shengjing Hospital of China Medical University and Jiangxi Provincial Children's Hospital applied UGHR; Xi'an Children's Hospital and Wuhan Children's Hospital applied FGAR. UGHR or FGAR is the conventional treatment methods in these hospitals, and implementation of this study does not require any special changes to the treatment methods.

In order to minimize the impact of age and time of onset on the results of this study, we conducted a stratified analysis of patient data. The data was divided into 
subgroups according to the onset time and age. Stratified analysis was made according to the symptom of blood stool.

\section{Enema reduction procedures}

The procedure of UGHR [10]: reduction was performed by two pediatric surgeons using ultrasound guidance. Patients were placed in a supine position, a Foley catheter was inserted via the anus, and the buttock was taped to prevent normal saline leakage. Under ultrasonography guidance, normal saline solution $\left(37{ }^{\circ} \mathrm{C}\right.$ to $\left.40{ }^{\circ} \mathrm{C}\right)$ was manually injected through the Foley catheter. The hydrostatic pressure was monitored by a sphygmomanometer attached to the Foley catheter. The maximum pressure was controlled under $100 \mathrm{mmHg}$. The success of reduction was determined by the disappearance of intussusception and the visualization of normal saline from the cecum to the ileum through the ileocecal valve or a normal saline distended ileum.

The procedure of FGAR: reduction was performed by a radiologist in the company of a pediatric surgeon using fluoroscopic guidance. Patients were placed in a supine position, a Foley catheter was inserted via the anus, and the buttock was taped to prevent air leakage. Under the fluoroscopic monitoring, air was injected through the Foley catheter. Pressure between 80 and $100 \mathrm{mmHg}$, controlled by a barometer, was applied. The success of reduction was determined by the disappearance of intussusception and the visualization of air from the cecum to the ileum through the ileocecal valve or an airdistended ileum.

Both of these two procedures were repeated no more than 3 attempts.

\section{Post-procedure treatments}

All patients in both treatment groups underwent repeated ultrasound to confirm the success of the enema reduction. After a successful reduction, the patient needs to be hospitalized for about $12 \mathrm{~h}$ until the next normal defecation.

\section{Effectiveness and safety assessment}

The success and recurrence rates were used to evaluate the effectiveness of enema reduction. The perforation rate was used to evaluate the safety of enema reduction. The efficacy of different treatment groups are further compared through subgroup and stratified analysis.

\section{Statistical analysis}

Data analysis was done using the data analysis function of Microsoft Office Excel (version OFFICE 2019 DESK TOP @Microsoft Corporation). Numerical descriptive data were presented as mean and standard deviation. The categorical descriptive data were reported as numbers $(N)$ and percentages (\%). Comparisons between the two groups were made using the Chi-square test and the Fisher test for $\mathrm{T}$ (theoretical frequency) $<5$ or $n$ (total number) $<40$. A value of $P<0.05$ was considered statistically significant.

\section{Results}

From November 2017 to October 2018, a total of 2591 intussusception cases were collected, according to the inclusion criteria; 2124 cases were finally enrolled in this study, including 1119 cases in the UGHR group and 1005 cases in the FGAR group (Fig. 1). The male to female ratio was 2:1. The patients' median age was 23.66 months. There was no significant difference in age $(P=0.28)$ or gender $(P$ $=0.52$ ) between the two groups (Table 1 ).

The overall success rate in this study was $94.54 \%$. The success rate of the UGHR group (95.80\%) was higher than that of the FGAR group $(93.13 \%)(P=0.007)$. The overall recurrence rate in this study was $9.93 \%$. The recurrence rate in the UGHR group (9.28\%) was lower than that of the FGAR group (10.65\%), but it was not statistically significant $(P=0.2980)$ (Table 1$)$.

The overall perforation rate in this study was $0.33 \%$. The perforation rate in the UGHR group was $0.36 \%$ higher than the FGAR group at $0.30 \%$, but the difference was not statistically significant $(P=0.9325)$ (Table 1$)$.

In order to analyze the effectiveness of UGHR and FGAR in patients with different onset times, the cases were divided into three subgroups according to the onset time: less than $12 \mathrm{~h}, 12 \mathrm{~h}$ to $24 \mathrm{~h}$, and more than 24 $h$. The success rate of UGHR group $(95.56 \%)$ was higher than that of the FGAR group (90.57\%) in the $12 \mathrm{~h}$ to 24 $\mathrm{h}$ group $(P=0.0049)$. There was no significant difference in the groups with onset times less than $12 \mathrm{~h}$ and more than $24 \mathrm{~h}$ (Table 2).

In order to analyze the effectiveness of UGHR and FGAR in patients of different ages, the cases were divided into two groups according to age: 4 to 24 months, and older than 24 months. The success rate of UGHR group was higher than that of FGAR group in age group 4 to 24 months $(P=0.0013)$. The group older than 24 months showed no significant differences in the success rate (Table 3).

We further analyzed patients with the symptom of bloody stool as a stratified analysis. The success rate of the UGHR group (91.91\%) was higher than that of FGAR group $(85.38 \%)(P=0.0085)$ (Table 4$)$. The recurrence rate of the UGHR group (3.46\%) was lower than that of the FGAR group (6.61\%), but it did not have significant statistical difference $(P=0.0804)$.

\section{Discussion}

UGHR and FGAR are two most commonly used nonsurgical treatment methods of uncomplicated 


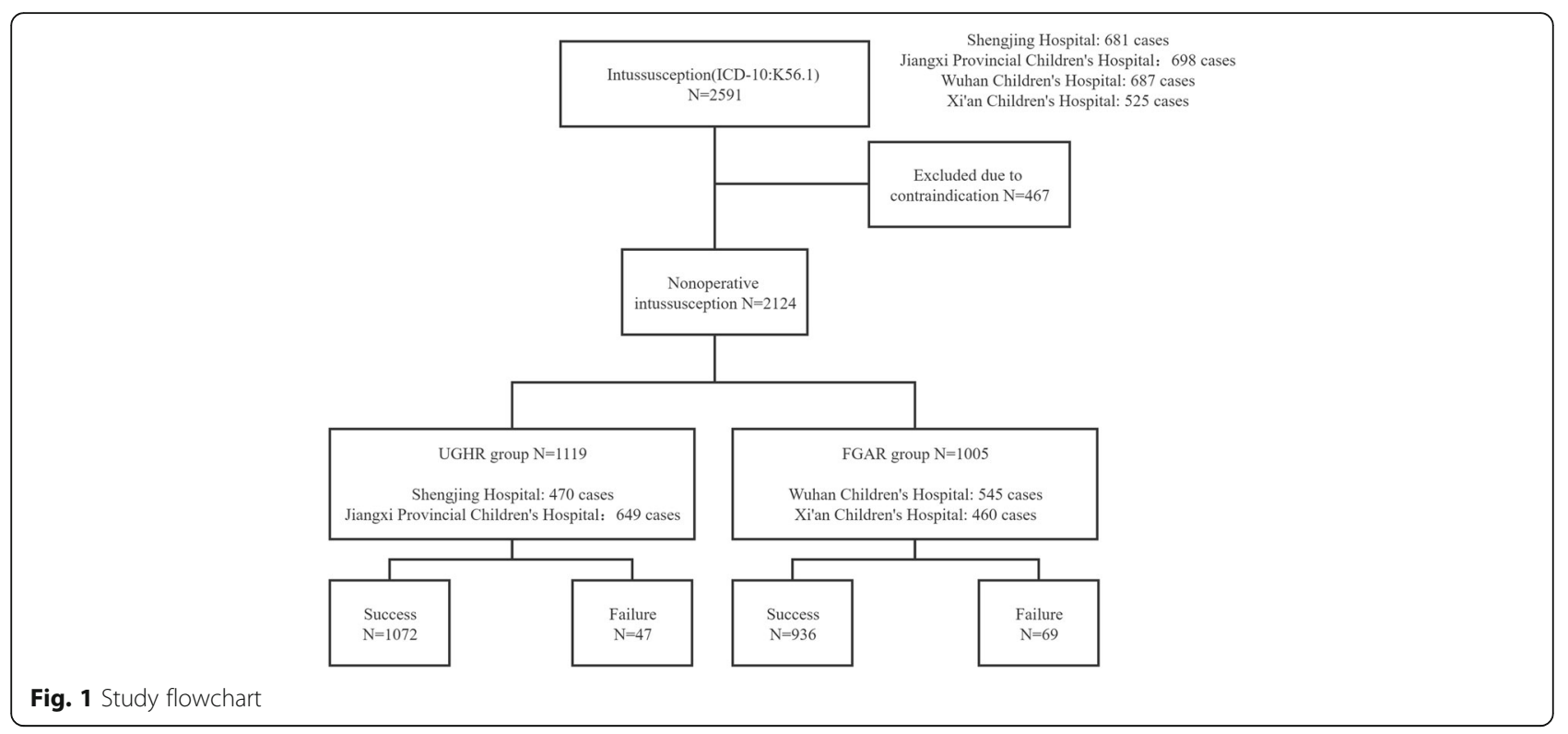

pediatric intussusception $[4,5,11]$. However, which of these two methods is more suitable for intussusception remains controversial. This research is the first multi-center and prospective study of enema reduction for the treatment of pediatric intussusception in the world. The results of this study showed that the success rate of UGHR is higher than FGAR, without significant difference in recurrence rate and perforation rate (Table 1). This demonstrates that UGHR is more effective than FGAR; and UGHR and FGAR are both safe methods for treatment of pediatric intussusception.

Intussusception is more common in children under 2 years of age, which may be caused by various etiology [12]. After 2 years of age, the incidence of intussusception declines. Therefore, stratified study was performed according to age and demonstrates that UGHR is more effective than FGAR for intussusception cases aged 4 to 24 months (Table 3). So, we considered that UGHR is more suitable than FGAR for intussusception patients under 2 years old.

In patients with intussusception, the edema and ischemia of the digestive tract worse with time, and the risk of perforation caused by enema treatment increases with time [1]. Therefore, we conducted a stratified analysis according to onset time and demonstrates that UGHR is more effective than FGAR for intussusception cases in the $12 \mathrm{~h}$ to $24 \mathrm{~h}$ group, while has no inferior efficacy to FGAR in other groups (Table 2). So, we considered that UGHR is more suitable than FGAR for intussusception patients with onset time between 12 and $24 \mathrm{~h}$.

Previous studies have shown that bloody stool is one of the risk factors associated with recurrence of pediatric intussusception $[13,14]$, and also indicates the severity of intussusception [1], which means that children with bloody stools have a higher risk of nonsurgical treatment failure. Therefore, we conducted a subgroup analysis of intussusception cases with the symptom of bloody stools

Table 1 Comparison between the UGHR and FGAR group

\begin{tabular}{|c|c|c|c|c|}
\hline & UGHR & FGAR & Total & $P$ value \\
\hline Total cases, $n$ & 1119 & 1005 & 2124 & \\
\hline Male, $n(\%)$ & 731 (65.33\%) & $670(66.67 \%)$ & 1401 & 0.5151 \\
\hline Female, $n(\%)$ & 388 (34.67\%) & 335 (33.33\%) & 723 & \\
\hline Mean age, month (range) & $23.2(4-156)$ & $24.7(4-146)$ & 23.66 & 0.2770 \\
\hline Mean onset time, month & 17.2 & 19.6 & 18.36 & \\
\hline Success cases, $n$ (\%) & 1072 (95.80\%) & $936(93.13 \%)$ & 2008 (94.54\%) & 0.0069 \\
\hline Recurrence cases, $n$ (\%) & $104(9.28 \%)$ & $107(10.65 \%)$ & 211 (9.93\%) & 0.2980 \\
\hline Perforation cases, $n$ (\%) & 4 (0.36\%) & 3 (0.30\%) & $7(0.33 \%)$ & 0.9325 \\
\hline
\end{tabular}


Table 2 Success rate in subgroups according to onset time

\begin{tabular}{llllll}
\hline Group & Outcome & UGHR & FGAR & Total & $\boldsymbol{P}$ value \\
\hline $0-12 \mathrm{~h}$ & Success & $504(97.30 \%)$ & $392(96.80)$ & 896 & 0.6500 \\
& Fail & 14 & 13 & 27 & \\
\multirow{2}{*}{$12 \mathrm{~h}-24 \mathrm{~h}$} & Success & $387(95.56 \%)$ & $384(90.57 \%)$ & 771 & 0.0049 \\
& Fail & 18 & 40 & 58 & \\
$>24 \mathrm{~h}$ & Success & $181(92.35 \%)$ & $160(90.91 \%)$ & 341 & 0.6164 \\
& Fail & 15 & 16 & 31 & \\
\hline
\end{tabular}

and demonstrate that UGHR is more effective than FGAR (Table 4). So, we considered that UGHR is more suitable than FGAR for intussusception patients with the symptom of bloody stools.

Until now, the studies including a large number of cases in the treatment of pediatric intussusception were almost retrospective single-center study with only one enema reduction method $[10,15,16]$. There were a few original studies comparing the effectiveness of UGHR and FGAR in the treatment of pediatric intussusception $[4,6]$. A randomized controlled trial (RCT) in 2018 of 124 pediatric intussusception cases in China showed that the success rate of UGHR (96.77\%) was higher than FGAR (83.87\%), which demonstrated that UGHR is more effective than FGAR [8]. A prospective cohort study in 2017 of 80 pediatric intussusception cases in Egypt showed that the success rates of FGAR and UGHR were equal (82.5\%), which demonstrated a similar effectiveness of UGHR and FGAR [6]. Both of these two studies had the disadvantage of a small number of cases (less than 200 cases). In this study, we collected more than 2000 cases of pediatric intussusception to compare the effectiveness and safety of UGHR and FGAR. The four Children's Medical Centers participating in this study are distributed in the northeast, southeast, western, and central regions of China, and the geographical distribution is relatively average. Therefore, this study avoids differences in region, culture, and lifestyle; thereby making the final results more credible and representative of the characteristics of Chinese pediatric intussusception cases.

FGAR has gained widespread acceptance worldwide as it has several advantages: easy to perform, quick, and clean [17].

Compared with FGAR, UGHR has some advantages. First, ultrasound can clearly show intussusception

Table 3 Success rate in subgroups according to age

\begin{tabular}{llllll}
\hline Group & Outcome & UGHR & FGAR & Total & $\boldsymbol{P}$ value \\
\hline $4-24$ months & Success & $702(95.77 \%)$ & $600(91.60 \%)$ & 1302 & 0.0013 \\
& Fail & 31 & 55 & 86 & \\
$>24$ months & Success & $370(95.85 \%)$ & $336(96.00 \%)$ & 706 & 0.9208 \\
& Fail & 16 & 14 & 30 & \\
\hline
\end{tabular}

masses (including edema of ileocecal valve) and can detect pathologically induced point or residual intussusception early [18, 19]. Previous study have showed ultrasound examination has significant advantages over fluoroscopy in terms of diagnostic specificity and sensitivity of intussusception [20]. This ensures patients receive accurate treatment as early as possible.

Second, UGHR is completely free of ionizing radiation, which is the main disadvantage of FGAR. Early studies focused less on radiation dose during enema reduction under fluoroscopy. Some studies show that the radiation dose of enema reduction under fluoroscopy one time is not enough to cause significant harm to the human body $[21,22]$. The small effect of ionizing radiation on the human body still has unexpected hazards, especially in children whose glands are more sensitive to radiation [23]. Acute pediatric intussusception is a common abdominal condition with a high rate of recurrence. In this study, the overall recurrence rate is $9.93 \%$ (Table 1). Therefore, this procedure often requires repeating. Under FGAR, the intussusception patients, their parents, and the medical staff can be exposed to ionizing radiation multiple times. The accumulation of radiation in the human body within a short period of time may also cause pathological changes; exact research has shown that receiving large doses of electromagnetic radiation can cause radiation-related malignancy [24, 25]. UGHR totally avoids radiation damage to human health, which is very meaningful for the protection of the patients, parents of the patients, and medical staff.

Despite the above-mentioned advantages, UGHR is not very widely applied because it requires special training. Our status survey in 2019 on enema reduction of pediatric intussusception in China showed that only $17.2 \%(22 / 128)$ hospitals used ultrasound to monitor the enema reduction, and pediatric surgeons were solely responsible for performing UGHR in only $36.4 \%(8 / 22)$ of these hospitals [4]. In Germany, pediatric surgeons can routinely use ultrasound to diagnose typical pediatric surgical diseases (including appendicitis and intussusception), and solely operate UGHR without the presence of an ultrasonographer [26]. In China, UGHR is not a routine training for pediatric residents, so most pediatric surgeons cannot perform UGHR alone. Having pediatric surgeons present to immediately judge and deal with unexpected intestinal perforation during enema can maximally decrease the delay of surgical treatment. Moreover, studies in the United Kingdom and Japan have supported the active role of the pediatric surgeon during enema reduction $[7,27]$. We believe that Chinese pediatric surgery residents also need ultrasound training, not only for treating intussusception, but also in clinical practice of other common disease. 
Table 4 Success rate and recurrence rate in patients with bloody stool

\begin{tabular}{lllll}
\hline & UGHR & FGAR & Total & P value \\
\hline Success cases, $n(\%)$ & $318(91.91 \%)$ & $257(85.38 \%)$ & $575(88.87 \%)$ & 0.0085 \\
Recurrence cases, $n$ (\%) & $11 / 318(3.46 \%)$ & $17 / 257(6.61 \%)$ & $28 / 575(4.87 \%)$ & 0.0804 \\
Total cases, $n$ (\%) & 346 & 301 & 649 & \\
\hline
\end{tabular}

\section{Limitation}

Some limitations of the present study should be acknowledged. First, this study is a prospective cohort study rather than a randomized control trial (RCT) comparing UGHR and FGAR. This may lead to potential selectivity bias and has a lower quality of evidence than $\mathrm{RCT}$, but this error is much less than in a single-center study. Second, the time range of this study is relatively short (between November 2017 and October 2018) and the number of cases included in the study was less than expected; extending the research time and increasing the number of cases may increase the quality of the research evidence. Thirdly, as a multi-center study, the data of the four participating medical centers may have technical bias, but the participating institutions are all at the first-line level of pediatric intussusception treatment in China. The mature technology and trained doctors can minimize such bias.

\section{Conclusions}

In conclusion, UGHR and FGAR are both safe, nonsurgical treatment methods for acute pediatric intussusception. UGHR is superior to FGAR, no radiation risk, and the success rate is higher without a difference in perforation rate, especially for patients aged 4 to 24 months.

\section{Abbreviations}

UGHR: Ultrasound-guided hydrostatic reduction; FGAR: Fluoroscopy-guided air reduction

\section{Acknowledgement}

Not applicable.

\section{Authors' contributions}

YZB conceived of the study, and participated in its design and coordination. STL collected the data from Shengjing Hospital of China Medical University, performed the statistical analysis, and contributed to draft the manuscript. XBT helped to draft the manuscript and revised the manuscript carefully. $\mathrm{HL}$ collected the data from Wuhan Children's Hospital. DC collected the data from Xi'an Children's Hospital. JL collected the data from Jiangxi Provincial Children's Hospital. All authors read and approved the final version of the manuscript.

\section{Funding}

This work was supported by LiaoNing Revitalization Talents Program [grant number XLYC1908008].

\section{Availability of data and materials}

All data generated or analyzed during this study are included in this published article.
Ethics approval and consent to participate

This study was approved by the Institutional Review Board of Shengjing Hospital of China Medical University (Approval No.2019PS601K), and has been exempted from the application for informed consent.

\section{Consent for publication}

Written informed consent for publication was obtained from all participants.

\section{Competing interests}

The authors declare that they have no competing interests.

\section{Author details}

${ }^{1}$ Department of Pediatric Surgery, Shengjing Hospital, China Medical University, No. 36 Sanhao Street, Heping District, Shenyang 110004, P. R. China. 'Department of Pediatric Surgery, Wuhan Children's Hospital, Wuhan, China. ${ }^{3}$ Department of Pediatric Surgery, Xi'an Children's Hospital, Xi'an, China. ${ }^{4}$ Department of Pediatric Surgery, Jiangxi Provincial Children's Hospital, Nanchang, China. ${ }^{5}$ The Pediatric Anorectal Group, Society of Pediatric Surgery, Chinese Medical Association, Shenyang, China.

Received: 22 October 2020 Accepted: 27 December 2020

Published online: 13 January 2021

\section{References}

1. Columbani PM, Scholz S. Chapter 85-intussusception. In: Arnold G. Coran editors. Pediatric surgery, 7th Edition. Amsterdam: Elsevier Inc.; 2012. p.10931110.

2. Stringer MD, Pablot SM, Brereton RJ. Paediatric intussusception. Br J Surg. 1992:79(9):867-76.

3. Schmit P, Rohrschneider WK, Christmann D. Intestinal intussusception survey about diagnostic and nonsurgical therapeutic procedures. Pediatric Radiol. 1999;29(10):752

4. Tang XB, Zhao JY, Bai YZ. Status survey on enema reduction of paediatric intussusception in China. J Int Med Res. 2019:47(2):859-66.

5. Hannon E, Williams R, Allan, Okoye B. UK intussusception audit: a national survey of practice and audit of reduction rates. Clin Radiol. 2014;69(4):344-9.

6. Ali A, Sheir H, Saied B, Wafa T, El-Ghazaly M. Pneumatic versus hydrostatic reduction in the treatment of intussusception in children. Ann Pediatric Surg. 2017;13(4):199-202

7. Chew R, Ditchfield M, Paul E, Goergen SK. Comparison of safety and efficacy of image-guided enema reduction techniques for paediatric intussusception: a review of the literature. J Med Imag Radiat Oncol. 2017; 61(6):711-7.

8. Xie $X L$, Wu $Y$, Wang $Q$, Zhao $Y Y$, Chen $G B$, Xiang B. A randomized trial of pneumatic reduction versus hydrostatic reduction for intussusception in pediatric patients. J Pediatric Surg. 2018;53(8):1464-8.

9. Sadigh G, Zou KH, Razavi SA, Khan R, Applegate KE. Meta-analysis of air versus liquid enema for intussusception reduction in children. Am J Roentgenol. 2015:205(5):W542-9.

10. Bai YZ, Qu RB, Wang GD, Zhang KR, Li Y, Huang Y, Zhang ZB, Zhang SC, Zhang HL, Zhou X. Ultrasound-guided hydrostatic reduction of intussusceptions by saline enema: a review of 5218 cases in 17 years. Am J Surg. 2006;192(3):273-5.

11. Daneman A. Intussusception. Part 2: an update on the evolution of management. Pediatric Radiol. 2004;34(2):97-108.

12. Mandeville K, Chien M, Willyerd FA, Mandell G, Bulloch B. Intussusception: clinical presentations and imaging characteristics. Pediatric Emerg Care. 2012;28(9):842.

13. Xie X, Wu Y, Wang Q, Zhao Y, Xiang B. Risk factors for recurrence of intussusception in pediatric patients: a retrospective study. J Pediatric Surg. 2018;53(11):2307-11. 
14. Guo WL, Hu ZC, Tan YL, Sheng M, Wang J. Risk factors for recurrent intussusception in children: a retrospective cohort study. Bmj Open. 2017; 7(11):e018604.

15. She YX. Treatment of intestinal invagination with particular emphasis on reduction by colonic insufflation. Report on 5110 cases. Chirurgie Pediatrique. 1982;23(6):373-8.

16. Guo JZ, Ma XY, Zhou QH. Results of air pressure enema reduction of intussusception: 6,396 cases in 13 years. J Pediatric Surg. 1986;21(12):1201-3.

17. Applegate KE. Intussusception in children: evidence-based diagnosis and treatment. Pediatric Radiol. 2009;39(2 Supplement):140-3.

18. Hryhorczuk AL, Strouse PJ. Validation of US as a first-line diagnostic test for assessment of pediatric ileocolic intussusception. Pediatric Radiol. 2009; 39(10):1075-9.

19. Verschelden P, Filiatrault D, Garel L, Grignon A, Perreault G, Boisvert J, Dubois J. Intussusception in children: reliability of US in diagnosis--a prospective study. Radiology. 1992;184(3):741-4.

20. Carroll AG, Kavanagh RG, Ni Leidhin C, Cullinan NM, Lavelle LP, Malone DE. Comparative effectiveness of imaging modalities for the diagnosis and treatment of intussusception: a critically appraised topic. Acad Radiol. 2017; 24(5):521-9.

21. Kaplan SL, Magill D, Felice MA, Edgar JC, Zhu X. Intussusception reduction: effect of air vs. liquid enema on radiation dose. Pediatric Radiol. 2017:47(11): 1-6.

22. Henrikson S, Blane CE, Koujok K, Strouse PJ, Dipietro MA, Goodsitt MM. The effect of screening sonography on the positive rate of enemas for intussusception. Pediatric Radiol. 2003:33(3):190-3.

23. Krissenko N. Overview of 1993 research activities in belarus related to the chernobyl accident. Stem Cells. 1997;15:207-10.

24. Parker L. Does radiation associated with diagnostic $\mathrm{CT}$ scans in children and young people increase their subsequent risk of developing cancer? Arch Dis Child Educ Pract Ed. 2013;98(6):239.

25. Wilson-Stewart K, Shanahan M, Fontanarosa D, Davidson R. Occupational radiation exposure to nursing staff during cardiovascular fluoroscopic procedures: A review of the literature. J Appl Clin Med Physics. 2018;19(6): 282-97.

26. Gfroerer S, Fiegel H, Rolle U. Ultrasound-guided reduction of intussusception: a safe and effective method performed by pediatric surgeons. Pediatric Surg Int. 2016;32(7):679-82.

27. Okazaki TOY, Nakazawa N, Kobayashi H, Kato Y, Lane GJ, Yamataka A, Miyano T. Reduction of intussusception in infants by a pediatric surgical team: improvement in safety and outcome. Pediatric Surg Int. 2006;22(11): 897-900.

\section{Publisher's Note}

Springer Nature remains neutral with regard to jurisdictional claims in published maps and institutional affiliations.

Ready to submit your research? Choose BMC and benefit from:

- fast, convenient online submission

- thorough peer review by experienced researchers in your field

- rapid publication on acceptance

- support for research data, including large and complex data types

- gold Open Access which fosters wider collaboration and increased citations

- maximum visibility for your research: over $100 \mathrm{M}$ website views per year

At $\mathrm{BMC}$, research is always in progress.

Learn more biomedcentral.com/submissions 